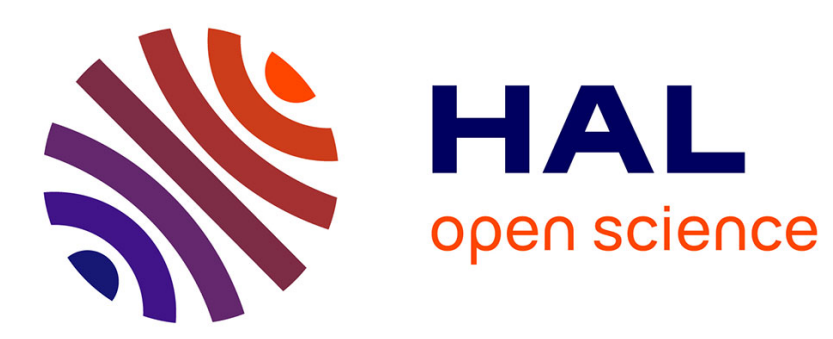

\title{
Foire forestière nationale d'Epinal - 27 avril - 5 mai 1974 - [.]revue Forestière Française, Rédaction
}

\section{- To cite this version:}

- [.]revue Forestière Française, Rédaction. Foire forestière nationale d'Epinal - 27 avril - 5 mai 1974. 1974, pp.79-80. 10.4267/2042/20808 . hal-03535049

\section{HAL Id: hal-03535049 \\ https://hal.science/hal-03535049}

Submitted on 19 Jan 2022

HAL is a multi-disciplinary open access archive for the deposit and dissemination of scientific research documents, whether they are published or not. The documents may come from teaching and research institutions in France or abroad, or from public or private research centers.
L'archive ouverte pluridisciplinaire HAL, est destinée au dépôt et à la diffusion de documents scientifiques de niveau recherche, publiés ou non, émanant des établissements d'enseignement et de recherche français ou étrangers, des laboratoires publics ou privés. 
- Enfin, la Centrale forestière se préoccupe de réorganiser la chaîne d'exploitation qui conduit du chantier au parc à bois de l'usine papetière utilisatrice.

Sur ce plan, l'action à entreprendre pourrait se diviser en trois étapes. Dans un premier temps, l'on devrait s'attaquer au problème de la réorganisation du stockage en usine. La modernisation des usines à pâte ne s'est pas accompagnée d'investissements suffisants concernant les parcs à bois. Il en résulte des grosses pertes dues à la fois à une absence de rotation de stocks et à des manutentions intempestives.

Dans un second temps, les responsables de l'approvisionnement envisageraient de régulariser le marché par la création d'aires de stockaqe et de conditionnement. Ces stations satellites permettraient de jouer sur les apports de bois (stockage momentané ou conditionnement sur place en plaquettes) et d'éviter tous les inconvénients liés à des réceptions par trop irrégulières. Enfin, il serait souhaitable qu'un même organisme s'occupât de la gestion globale de l'ensemble de la chaîne d'approvisionnement : du bois sur pied jusqu'à la dernière transformation mécanique, c'est-à-dire la mise en plaquettes. Rappelons qu'à l'heure actuelle, la Centrale forestière n'assure pas la mise en plaquettes qui fait partie des prérogatives de l'usine.

L'adoption de la solution ainsi esquissée permettrait :

- d'étendre la notion de rentabilité à l'ensemble de la chaîne de production ce qui entraînerait une localisation plus aisée des secteurs directement compressifs et corrélativement une meilleure efficacité des actions entreprises:

- d'atteindre un équilibre infiniment souhaitable entre les achats, les exploitations, les livrassons et la consommation aux divers moments de l'année.

- Le troisième et dernier volet de l'action entreprise se rapporte à la sylviculture. Le groupe de la Cellulose du Pin se préoccupe constamment d'apporter son soutien à toutes les activités de recherche sylvicole concernant le pin maritime. Après les améliorations issues de la fertilisation de la ligniculture, on attend de l'amélioration génétique un nouvel accroissement des rendements.

Pour l'heure, donc, l'exploitation landaise tend a se rationaliser, mais bien que les réalisations à mettre à son actif soient non négligeables, et même souvent spectaculaires, on peut considérer que le travail de décantation qui s'opère actuellement n'a pas encore trouvé son aboutissement.

Gageons cependant qu'à court terme l'on pourra réellement parler dans le massif landais de " méthodes rationnelles d'exploitation forestière".
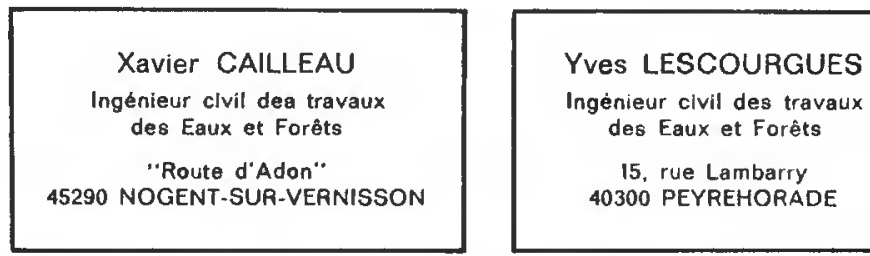

\section{FOIRE FORESTIĖRE NATIONALE D'ÉPINAL - 27 AVRIL - 5 MAI 1974}

Comme toute préfecture, Epinal chercha à développer sa foire exposition annuelle créée en 1948.

En 1960 l'accent y fut mis pour la première fois sur la forêt et elle fut inaugurée par M. Merveilleux du Vignaux alors Directeur général des Eaux et Forèts.

Dans les Vosges la forêt s'imposait : 250000 ha boisés sur 586000 ha $(0,70$ ha de forèt par habitant) (forêts domaniales $1 / 4$ - communales $1 / 2$ - particulières 1/4).

Les massifs qui entourent Epinal marquent la transition entre les hêtraies et les chênaies du plateau lorrain et les pineraies et les sapinières de la montagne réputées les unes et les autres pour leur qualité (hètraie des Côtes de Meuse, chênaie de Darney, sapinières de La Bresse, Gérardmer, du Val de Senones). 